\title{
Experimental and Virtual Studies in Mechanical Applications of PP-RCT Pipes with Armored Materials
}

\begin{abstract}
MARIA CRISTIANA ENESCUㄹ, ELENA VALENTINA STOIAN², ALEXIS NEGREA ${ }^{1}$, SIMONA MIHAI ${ }^{1}$, IVONA PETRE ${ }^{1}$, CARMEN OTILIA RUSANESCU2*

${ }^{1}$ Valahia University of Targoviste, Faculty of Materials Engineering and Mechanics, 13 Sinaia Alley, 130004, Targoviste, Romania ${ }^{2}$ Politehnica University of Bucharest, Faculty of Biotechnical Systems Engineering, 313 Splaiul Independentei, 060042, Bucharest, Romania

The new generation of newly developed materials, namely the high-crystallinity and high temperature polypropylene random copolymer, called PP-RCT, increases the crystalline capability of polypropylene, which allows pipes produced from this material to operate at higher pressures at elevated temperatures. Pressure tests on pipes made of PP-RCT materials show a resistance over a period of 50 years at $700^{\circ} \mathrm{C}(1580 \mathrm{~F}) 5$ MPa (725 psi) compared with 3.2 MPa (464 psi) for standard materials PPR. By reinforcing PP-RCT with aluminum, glass and basalt composite results in a more resistant structure. As a result of the traction tests, it was found that in all three samples the tensile strength exceeds the manufacturer s limit (10 - 12.7 MPa), the values obtained being: $\sigma_{t 1}=8 \mathrm{MPa}$ - sample no. $1 ; \sigma_{t 2}=13 \mathrm{MPa}$ - sample no. 2; $\sigma_{t 1}=11 \mathrm{MPa}$ - sample no. 3. The fiber glass insert is less resistant, the best variant being the basal insect sample $\left(\sigma_{t 2}=13 \mathrm{MPa}\right)$. Elongation at break for specimen no. 3was recorded at $0.027 \mathrm{~mm} / \mathrm{mm}$. Tests on these material combinations were performed for stretching and flexing requests and compared to 3D created virtual models. Simulations of internal pressure behavior were also performed for different material configurations and the results were compared with the experimental data and the data supplied by the manufacturers.
\end{abstract}

Keywords: einforced composite, polypropylene, traction test, simulation, bending test

Plastic materials quickly replace copper pipes and fittings in sanitary and heating systems around the world. Over the past 20 years, pressure pipe systems made from random polypropylene copolymer (PPR) have been widely adopted by the sanitary and heating industry in many countries around the world. However, while the components of the system have been progressively improved during this period, the base plastic (polypropylene) used has remained essentially the same [1-4].

PP-RCT is a polypropylene-random copolymer that possesses a unique morphology. Compared to the standard PPR, which shows only the monoclinic form ( $\alpha$-form), the crystalline structure of PP-RCT consists of a high degree of hexagonal form ( $\beta$ form) and to a small extent of the monoclinic form.

The presence of both crystalline forms can be easily seen in the melting behavior of PP-RCT because it shows two distinct peaks in the DSC plot (fig. 1) of the second heating curve.

The formation of the hexagonal crystal structure is performed using a special nucleation technology (for crystals $\beta$ ). The addition of a nuclear agent provides crystallization nuclei which greatly increase the growth rate of $\beta$ crystals and thus favor the formation of a stable hexagonal crystalline structure [4-6].

The special $\beta$-nuclear agent not only promotes the development of the hexagonal structure but also leads to a fine crystal structure and a homogeneous distribution of crystallite size (fig. 2), attributes that positively affect the mechanical characteristics of a material.

Figure 2 Nucleation $\beta$ results in very small crystals, predominantly hexagonal structures, and a uniform distribution of crystalline (left) compared to the nonnucleated monoclinic structure of PP (right)

* elenastoian22@gmail.com, rusanescuotilia@gmail.com
One of the most important properties of a polymeric material used for hot and cold water is resistance to internal pressure for different temperatures. The internal pressure behavior assessment method is standardized and described in ISO 9080 and was performed on Beta-PPR RA7050 polypropylene produced by Dynatherm PIPE UPG. The Beta-PPR RA7050 material is part of the new class of materials.

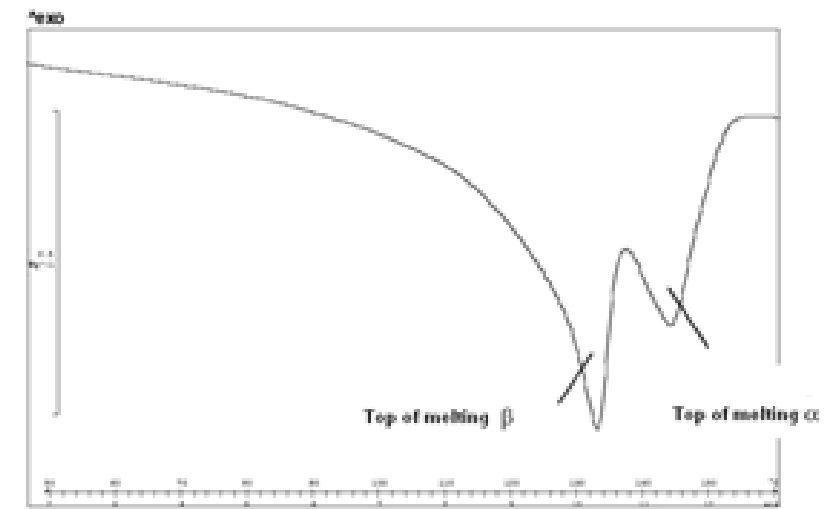

Fig. 1. DSC Diagram of the Second PP-RCT Heat Curve (measured on Beta-PP-R RA7050)

This investigation was carried out at the accredited Swedish Bodycote Polymer AB and tested 150 pipelines at 5 different temperatures. The highest test temperature was $110^{\circ} \mathrm{C}(230 \mathrm{~F})$ and test times were greater than one year [7-10].

\section{Experimental part}

Materials and methods

PP-RCT pipelines provide a better flow ability of all exhaust points around the building and are highly appreciated by installers and designers in the field due to the thin-walled construction. 


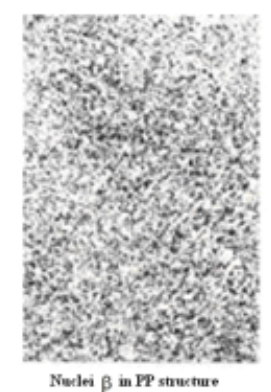

Niwlei $\beta$ in IP structure

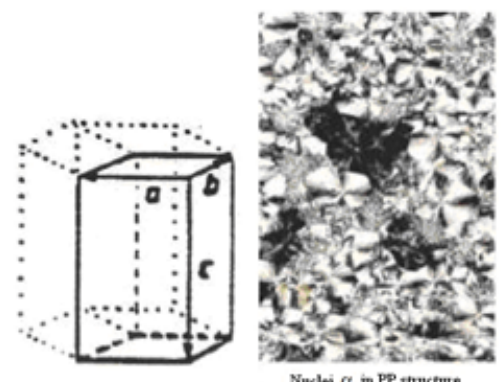

Nowien $\alpha$ in PP troctwe

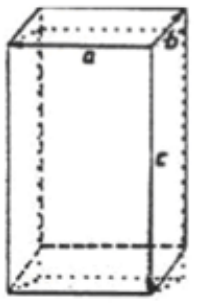

Fig. 2 Nucleation $\beta$ results in very small crystals, predominantly hexagonal structures, and a uniform distribution of crystalline (left) compared to the nonnucleated monoclinic structure of PP (right)
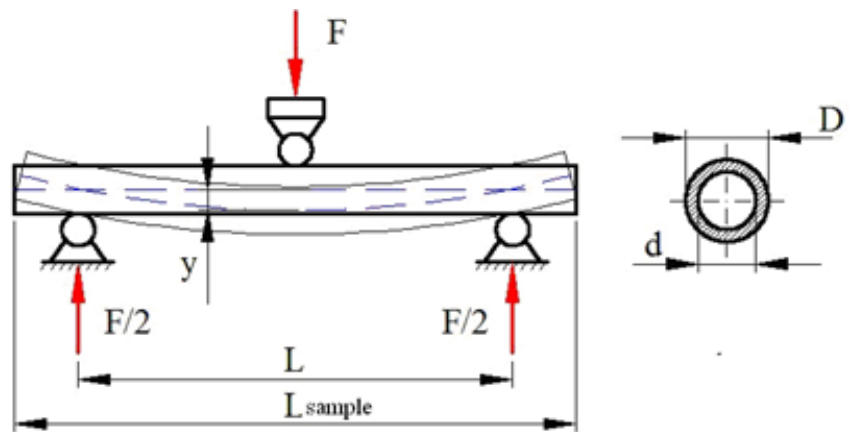

3 - PPR-RCT reinforced with aluminum insert.

Fiber-reinforced samples are taken from pipes having this insert positioned at half the wall thicknesses, as well as arched basalt insert. Samples taken from aluminum reinforced pipes have this insert positioned on the exterior of the pipe and are covered with a thin layer of polypropylene [9-11].

The mechanical tests performed were three-point bending and traction.

Measurement of mechanical properties as a result of bending and traction applications was carried out at the Prototyping and eco-design in renewable energy systems laboratory at the Institute of Multi-disciplinary Scientific and Technological Research at VALAHIA University in Targoviste (ICSTM-UVT) multifunctional MTS Bionix, equipped with the necessary kits for testing the three-point bending strength and testing the tensile strength.

\section{Determination of bending strength}

Determination of the bending strength [1-16] of the sample $(\sigma i)$ in the software of the Bionix MTS system is based on the following equations:

$$
\begin{gathered}
\mathrm{R}_{\mathrm{i}}=\frac{\mathrm{M}}{\mathrm{W}}[\mathrm{MPa}] \\
\mathrm{M}=\frac{\mathrm{F} \cdot \mathrm{L}}{4}[\mathrm{Nmm}] \text { and } \mathrm{W}=\frac{\pi \cdot\left(\mathrm{D}^{4}-\mathrm{d}^{4}\right)}{32 \cdot \mathrm{D}}\left[\mathrm{mm}^{3}\right](2) \\
\mathrm{R}_{\mathrm{i}}=\frac{8 \cdot \mathrm{F} \cdot \mathrm{L}}{\pi \cdot\left(\mathrm{D}^{3}-\mathrm{d}^{3}\right)}[\mathrm{MPa}]
\end{gathered}
$$

where:

$\mathrm{M}$-bending strength [ $\mathrm{Nmm}$ ]; $\mathrm{W}$-resistance module of the sample section [ $\left.\mathrm{mm}^{3}\right] ; \mathrm{F}$ - is the applied force [N]; L the distance between the sample points [mm]; D - the outside diameter of the sample [mm]; $d$ - the inner diameter of the sample [mm].

And the modulus of elasticity of the sample material, with the equation:

$$
\mathrm{E}=\frac{\mathrm{F} \cdot \mathrm{L}^{3}}{48 \cdot \mathrm{y} \cdot \mathrm{I}_{z}}=\frac{64 \cdot \mathrm{F} \cdot \mathrm{L}^{3}}{48 \cdot \mathrm{y} \cdot \pi \cdot\left(\mathrm{D}^{4}-\mathrm{d}^{4}\right)}[\mathrm{MPa}]
$$

with:

$$
I_{z}=\frac{\pi \cdot\left(D^{4}-d^{4}\right)}{64}\left[m m^{4}\right]
$$

where:

$y$ - the arrow that the test makes under the force of the machine $[\mathrm{mm}]$.

The value of the arrow (fig. 3 ) is determined from the chart generated by the BIONix multifunctional system workbook following the test bending test.

Fig. 4 Specimens from the chosen pipes

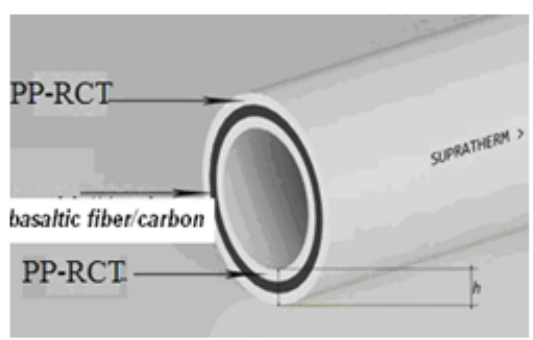

The distance between the supports for the three-point bending device is $24 \mathrm{~mm}$.

\section{Results and discussions}

\section{Flexural bending}

The MTS Bionix multifunction system features the standard three-point bending resistance system. The calculation device for determining the maximum flexural 


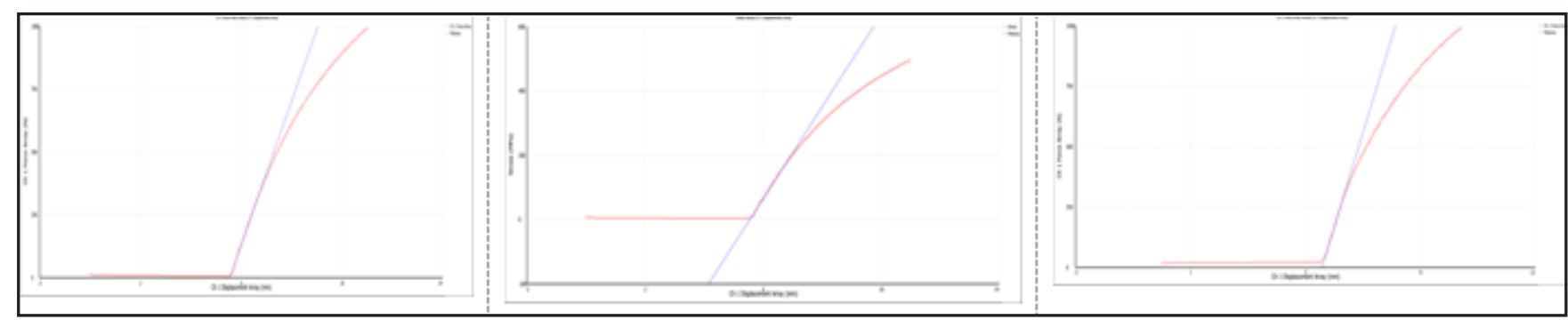

Fig.5 Curve force applied - arrow PP

Fig.6 Curve tensile - arrow PP with aluminum with fiber glass insertion
Fig. 7 Curve force applied - arrow PP with basaltic insertion

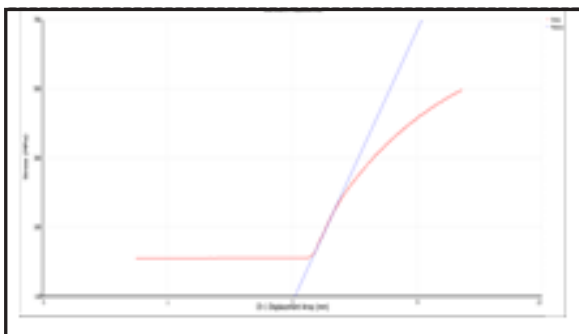

Fig. 8 Curve tensile - arrow PP with basaltic

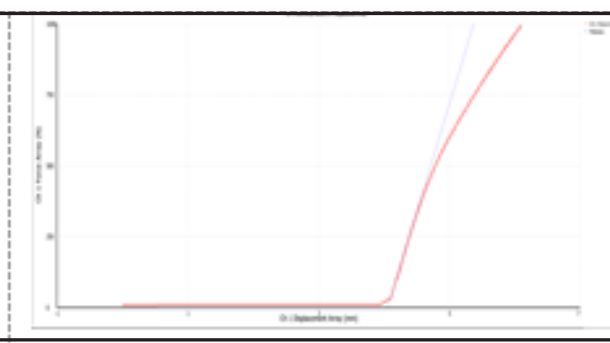

Fig.9 Curve force applied - arrow PP with aluminum insertion

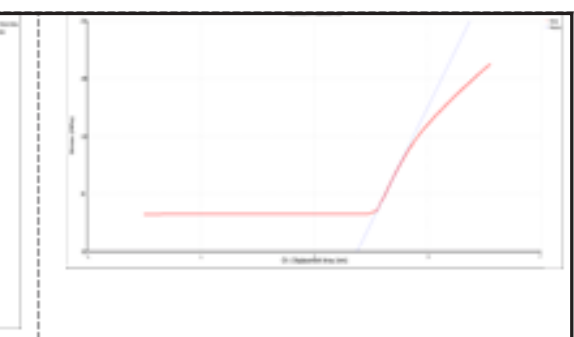

Fig.10 Curve tensile - arrow PP with aluminum insertion tension, maximum force and maximum arrow is based on formulas 1-5. Various graphical results (tensile -applied force, tensile-arrow, applied force - arrow, etc.) can be obtained. What is important is that for a specimen of material with some dimensional characteristics the variation of the arrow (displacement) can be determined depending on the maximum force applied and the maximum flexural tension $[17,20,21]$.

In the figures (5-10), the results obtained for the bending test of the three types of specimens are presented.

The graphs of figures 5 to 10 generated by the measurement system have some particularities. The measuring device consists of the two supports mounted on the fixed (bottom) part of the system on which the sample is placed and the active, movable part mounted on the upper crosspiece. The measuring system establishes a zero point of the position of the force application device, point where, if the movement is upward (traction, for example) the displacements and forces values will be with the plus sign and if the movementhas them down (bending, compression) then the values of displacements, applied forces and voltages will be displayed minus [18-24].

Also, the shift values (arrow) on the abscissa are ordered from right to left starting from the zero point and the ordered values of applied force and tensions will be ordered from top to bottom. Both graphs (force-displacement and tension-displacement) have a linear portion parallel to the abscissa, the portion corresponding to the empty distance traveled from the zero point until the roll of the force applicator reaches the specimen. The second portion represents the applied force-displacement and tensiondisplacement force curve. The values recorded in the graphs in figures 5-10 are for the specimens of the above dimensions and are tabulated (tables 1-3).

\begin{tabular}{|c|c|}
\hline \multicolumn{2}{|l|}{ Results } \\
\hline Maximum load & $\mathrm{kN}$ \\
\hline Maximum Strength & $\mathrm{kN} / \mathrm{mm}^{2}$ \\
\hline Strain At Break & $\mathrm{mm} / \mathrm{mm}$ \\
\hline Modulus & $\mathrm{MPa}$ \\
\hline Offset Yield Strength $(0.2 \%)$ & $\mathrm{kN} / \mathrm{mm}^{2}$ \\
\hline
\end{tabular}

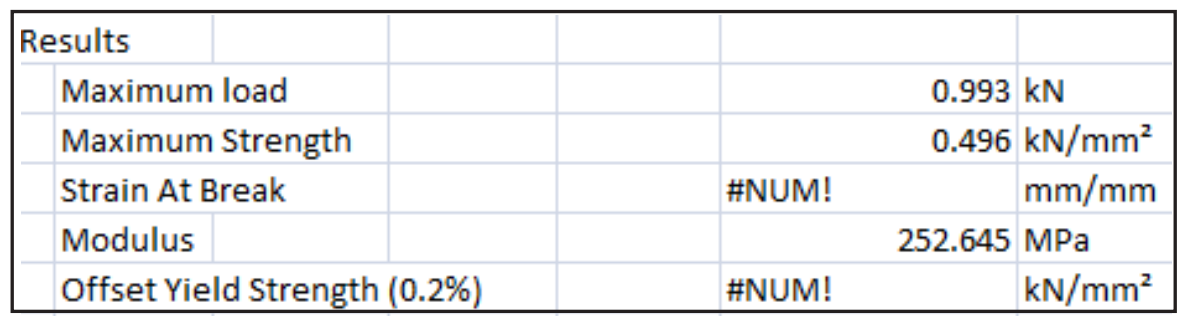

Table 1

RESULTS OF PP WITH FIBER GLASS INSERTION ( $D=20 \mathrm{~mm}, \mathrm{~d}=13.4 \mathrm{~mm})$

RESULTSOF PP WITH BASALTIC INSERTION ( $D=20 \mathrm{~mm}, \mathrm{~d}=13.4 \mathrm{~mm}$ )

\begin{tabular}{|l|r|r|}
\hline \multicolumn{2}{|l|}{ Results } & \\
\hline Maximum load & & $0.995 \mathrm{kN}$ \\
\hline Maximum Strength & & $0.21 \mathrm{kN} / \mathrm{mm}^{2}$ \\
\hline Strain At Break & \#NUM! & $\mathrm{mm} / \mathrm{mm}$ \\
\hline Modulus & & $128.849 \mathrm{MPa}$ \\
\hline Offset Yield Strength $(0.2 \%)$ & \#NUM! & $\mathrm{kN} / \mathrm{mm}^{2}$ \\
\hline
\end{tabular}

Table 3

RESULTS OF PP WITH ALUMINIUM INSERTION ( $D=25 \mathrm{~mm}, \mathrm{~d}=16.2 \mathrm{~mm}$ ) 


\section{Determination of tensile strength}

The tensile strength of the sample ( $\sigma r)$ was tested on the Bionix MTS system and calculated with the soft equations:

- conventional characteristic curve:

$$
\begin{aligned}
& \sigma=\frac{\mathrm{F}}{\mathrm{A}_{0}}[\mathrm{MPa}] \\
& \varepsilon=\frac{\Delta \mathrm{L}}{\mathrm{L}_{0}}[\mathrm{~mm}]
\end{aligned}
$$

- real characteristic curve

$$
\begin{aligned}
\sigma & =\frac{\mathrm{F}}{\mathrm{A}_{\mathrm{r}}}[\mathrm{MPa}] \\
\varepsilon & =\frac{\Delta \mathrm{L}}{\mathrm{L}_{0}}[\mathrm{~mm}]
\end{aligned}
$$

where:

$A_{0}$ - the area of the initial section of the specimen; $L_{\text {- }}$ the initial length between the two cross sections of the specimen; $A_{r}$ - the area of the real momentary section of the specimen;

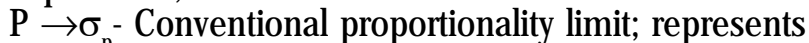
the voltage for which the deviation between the current elastic modulus Eo and the initial elastic modulus $E_{0}$ is $10 \%$. Deviation is calculated with the formula:

$$
\sigma_{10}=\frac{E_{0}-E_{\sigma}}{E_{0}}[\mathrm{MPa}]
$$

$\mathrm{E} \rightarrow \sigma_{e^{-}}$the technical elastic limitfor a prescribed linear residual specific deformation is usually considered $\varepsilon_{\mathrm{r}}=$ $0.01 \%$ and is noted $\sigma$

For materials that have no apparent flow limitation, it is conventional:

$-\mathrm{R}_{\mathrm{n}}$ - the conventional flow limit for a non-proportional elongation prescribed by $0.2 \%$;

$-R_{r 02}$ - the residual flow limit for a residual elongation prescribed $0.2 \%$.

$-R \rightarrow \sigma_{r}\left(R_{m}\right)$ the breaking strength is the ratio between the maximum force to be achieved in the point $R$ and the area of the initial cross section of the specimen:

$$
\sigma_{\mathrm{r}}=\frac{\mathrm{F}_{\max }}{\mathrm{A}_{0}}[\mathrm{MPa}]
$$

The specimens for measuring the mechanical properties of traction are three.

The dimensions of speciments:

- specimen no.1: $L_{\text {sample }} \times D \times d=150 \times 20 \times 13.4 \mathrm{~mm}$.

-specimen no 2: $L_{\text {sample }} \times D \times d=150 \times 20 \times 13.4 \mathrm{~mm}$.

- specimen no 3: $\mathrm{L}_{\text {sample }}^{\text {sample }} \times \mathrm{D} \times \mathrm{d}=150 \times 25 \times 16.2 \mathrm{~mm}$.

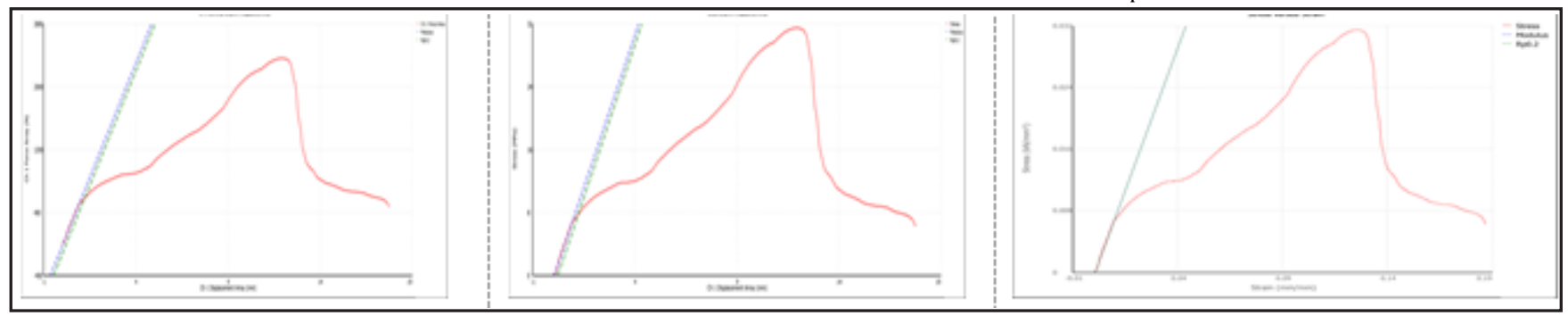

Fig.11 Curve applied force - elongation for Fig.12 Curve tensile - elongation for the the specimen no.1

\begin{tabular}{|l|c|}
\hline \multicolumn{2}{|c|}{ the specimen no.1 } \\
\hline Results & $2.360 \mathrm{kN}$ \\
\hline Tensile load & $0.031 \mathrm{kN} / \mathrm{mm}^{2}$ \\
\hline Tensile Strength & $0.126 \mathrm{~mm} / \mathrm{mm}$ \\
\hline Strain At Break & $759.613 \mathrm{MPa}$ \\
\hline Modulus & $0.008 \mathrm{kN} / \mathrm{mm}^{2}$ \\
\hline Offset Yield Strength (0.2\%) & \\
\hline
\end{tabular}

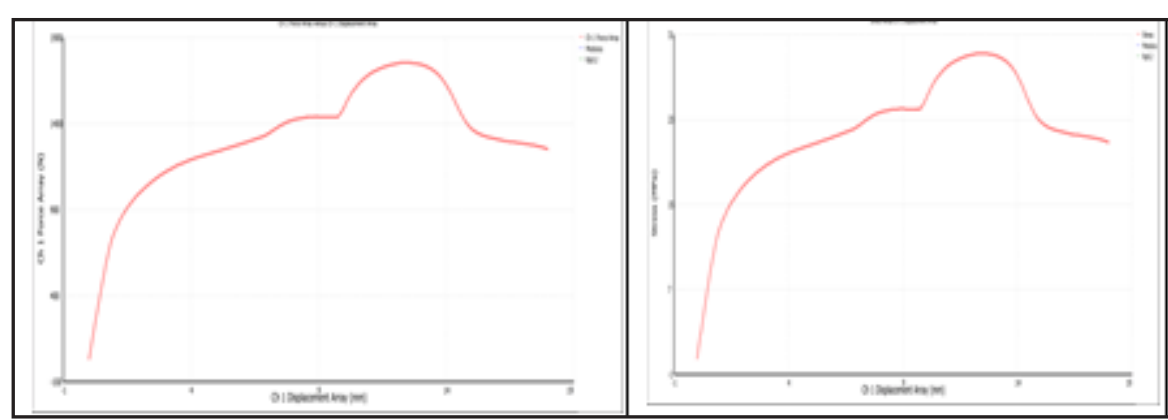

Fig.14 Curve applied force - elongation for the specimen no.2

Fig.15 Curve tensile - elongation for the specimen no.2

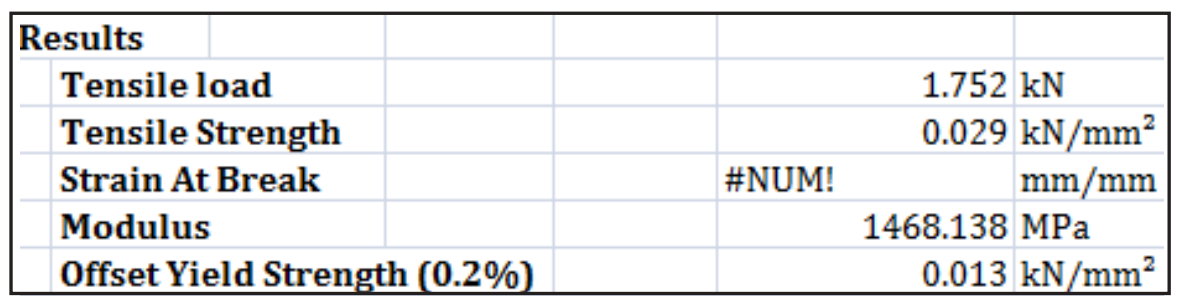

Fig.13 Curve tensile - equivalent elongation for the specimen no.1

Table 4

RESULTS OF TENSILE STRENGTH FOR THE SPECIMENT no.1. 


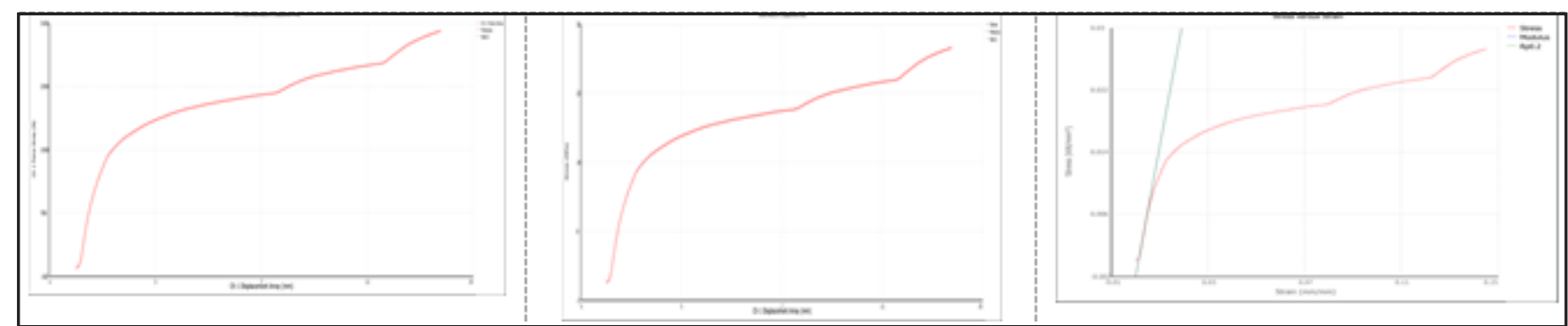

Fig.17 Curve applied force - elongation for Fig.18 Curve tensile - elongation for the the specimen no.3 specimen no.3
Fig.19 Curve tensile - equivalent elongation for the specimen no. 3

\begin{tabular}{|l|c|}
\hline Results & \\
\hline Tensile load & $3.000 \mathrm{kN}$ \\
\hline Tensile Strength & $0.027 \mathrm{kN} / \mathrm{mm}^{2}$ \\
\hline Strain At Break & \#NUM! \\
\hline Modulus & $1748.527 \mathrm{MPa} / \mathrm{mm}^{\mathrm{MPa}}$ \\
\hline Offset Yield Strength (0.2\%) & $0.011 \mathrm{kN} / \mathrm{mm}^{2}$ \\
\hline
\end{tabular}

Table 6

RESULTS OF TENSILE STRENGTH FOR THE SPECIMEN no.3

The figures show the results obtained for the traction test of the three specimens.

As a result of these traction tests it was found that not all three samples withstand the tensile strength exceeding the manufacturer's limit (10 - 12.7 MPa), the values obtained being: $\sigma_{t 1}=8 \mathrm{MPa}$ - specimen no.1; $\sigma_{t 3}=13 \mathrm{MPa}$ - specimen no. $2 ; \sigma_{\mathrm{t} 1}=11 \mathrm{MPa}$ - specimen no.3;

The glass fiber insert test is less resistant. The best variant is the specimen with basaltic insertion $\left(\sigma_{\mathrm{t} 2}=13 \mathrm{MPa}\right)$.

Elongation at break for specimen no. 3 was recorded at $0.027 \mathrm{~mm} / \mathrm{mm}$.

Virtual Pressure Internal Pressure Tests for PP-RCT Pipes

Pressure tests on pipes made of PP-RCT materials demonstrate resistance over a period of 50 years at $700^{\circ} \mathrm{C}$ (1580F) of $5 \mathrm{MPa}$ ( $725 \mathrm{psi}$ ) compared with $3.2 \mathrm{MPa}$ (464 psi) for standard PP-R materials.

Virtual samples were designed for virtual analysis:

- PP-RCT sample with glass fiber insert;

- PP-RCT sample with aluminum insert.

For the basalt insertion sample, it was not possible to establish the mechanical properties of the basalt.

Virtual analysis of the composite glass fiber insert sample

The PP-RCT sample with glass fiber $[18,19]$ insert is made up of three layers: PP-glass fiber-PPR with identical thicknesses of the actual pipe (fig. 20).

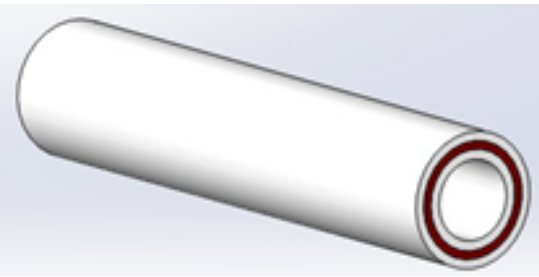

Fig.20 Virtual probe from PP-RCT with composite fiber insert

For this sample, an internal pressure of $5 \mathrm{MPa}$ was applied. The results obtained are shown in figures (21-23).

The maximum stress (with $\sigma_{\text {yon }}=14.0 \mathrm{MPa}$ ) is located inside the pipe where the stress was applied and is less than the material flow that was determined experimentally $\left(\sigma_{c}=17 \mathrm{MPa}\right) .[8]$

Equivalent displacements (deformations) are small ( $\delta$ $=0.037 \mathrm{~mm}$ ). The FOS safety factor is above the optimum value (3).

Virtual analysis of the aluminum insert sample

The PP-RCT Aluminum Injection Sample is made up of three layers: PP-Aluminum-PPR with identical thicknesses to the actual pipe (fig. 24)

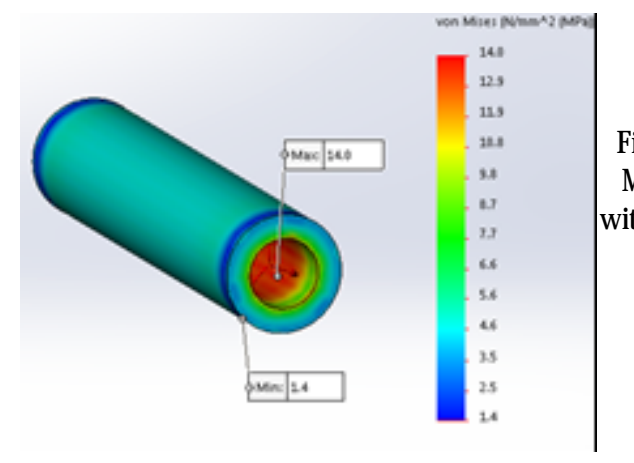

Fig.21 Tensile von Mises for PP-RCT with composite fibre insertion

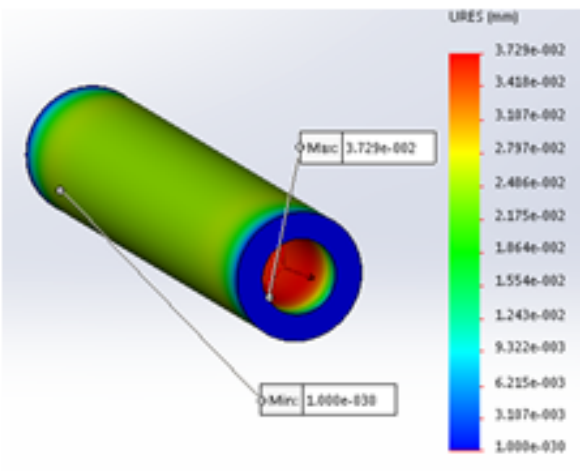

Fig.22 Equivalent displacements for PP-RCT with composite fiber insertion

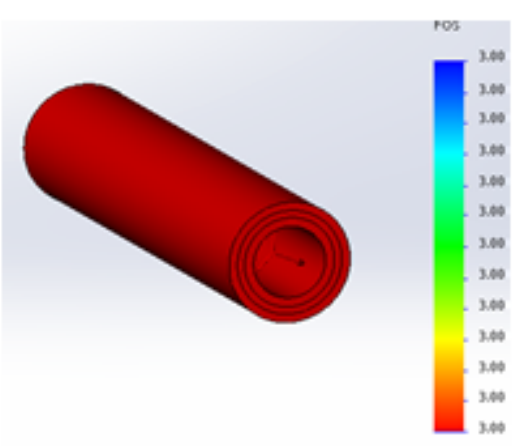

Fig. 23 The FOS safety factor for PP-RCT with composite fiber insertion

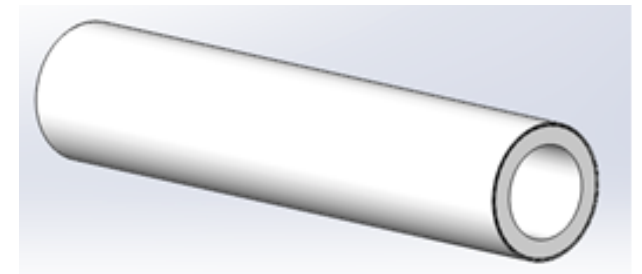

Fig. 24 Virtual probe from PPR-RCT with aluminum insert 


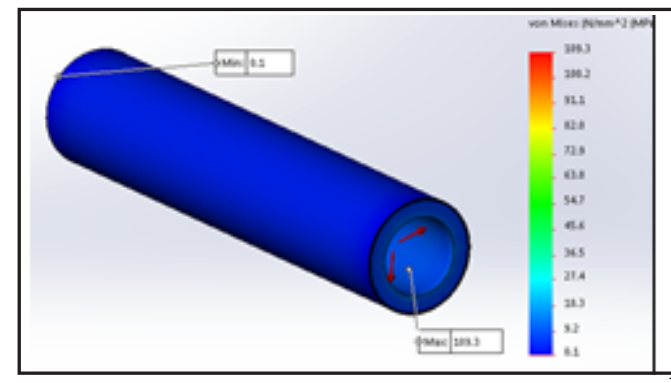

Fig.25 Tensile von Mises for PP-RCT with aluminium insertion

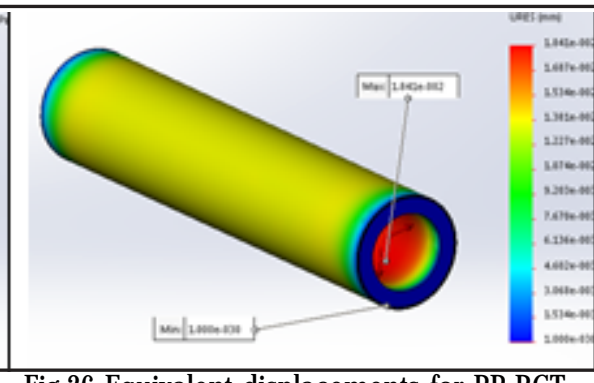

Fig.26 Equivalent displacements for PP-RCT with aluminium insertion
For this sample, an internal pressure of $5 \mathrm{MPa}$ was applied. The results obtained are presented in figures (2527).

The maximum stress (with $M=109.3 \mathrm{MPa}$ ) lies inside the pipe where the stress was applied and is high in relation to the flow rate of the material from which the experiment was determined $(\sigma \mathrm{c}=17 \mathrm{MPa})$.

However, the equivalent displacements (deformations) are small $(\delta=0.018 \mathrm{~mm})$, which means a calculation error because the FOS safety factor is also above the optimal value (3).

\section{Conclusions}

As a result of the traction tests, it was found that in all three samples the tensile strength exceeds the manufacturer's limit (10 - 12.7 MPa), the values obtained being: $\sigma t_{1}=8 \mathrm{MPa}$ - sample no. $1 ; \sigma t=13 \mathrm{MPa}$ - sample no. 2; $\sigma \mathrm{t}_{1}=11 \mathrm{MPa}$ - sample no. 3. The fiber glass insert is less resistant, the best variant being the basal insect sample $(\sigma t=13 \mathrm{MPa})$. Elongation at break for specimen no. 3 was recorded at $0.027 \mathrm{~mm} / \mathrm{mm}$.

Clearly, the PP-RCT pipeline systems offer a number of important benefits. This can be illustrated by an example from the Middle East, where it is common practice to install the water tank on the roof and use gravity to distribute water around the building. The use of PPR-RCT thin-walled pipes ensures better flowability of all exhaust points around the building and is highly appreciated by installers and designers in the industry.

PP-RCT pipeline pressure tests demonstrate a resistance over a period of 50 years at $70^{\circ} \mathrm{C}(1580 \mathrm{~F})$ of $5 \mathrm{MPa}(725$ psi) compared with $3.2 \mathrm{MPa}$ (464 psi) for standard materials PP-R.

Offering an improvement of over $50 \%$ over the long term, PP-RCT allows designers to build thinner pipes, and smaller pipe sizes can also be used in some situations. This results in a superior hydraulic capacity of the pipe or the possibility of applying a higher pressure than with the standard PPR.

\section{References}

1.GHITA ,E., GILLICH, G., R., BORDEAU, I., VODA, M., TROI,V., Aspecte ale comportarii polimerilor la solicitari de tractiune, Mat.Plast. 44, no. 2, 2007.

2.GHEORGHIU, H., HADAR, A., CONSTANTIN, N., Calculul structurilor din materiale izotrope si anizotrope, Editura Printech, Bucuresti, 1998, p. 59.

3. GILLICH, G.R., SAMOILESCU, G., BERINDE, F.C., CHIONCEL, C.P., Determinarea experimentala a caracteristicii de rigiditate si a modulului de elasticitate a cauciucului utilizând reprezentarea timpfrecventa, Mat. Plast., 44, no.1, 2007.

4.GHIOCA, P., BUZDUGAN, E., CINCU, C., IANCU L., ZAHARIA, C., ZECHERU, T.,Compozite politeilenice antisoc, Mat.Plast., 44, no.3, 2007, p.175.

5.RUSANESCU, C. O., JINESCU, C., RUSANESCU, M., ENESCU, M. C., ANGHELINA, F. V., STOIAN, E. V., DESPA, V., Mathematical Modelling of the Stress-Strain Curve for 31VMn12 Ecological Steel, Mat.Plast., 54, no. $3,2017$.
6.RUSANESCU, C.O., RUSANESCU, M., ANGHELINA, FL. V., Optoelectronics and advanced materials Rapid communications, 7, no.11-12, 2013, p. 947-951.

7.RUSANESCU, C. O., RUSANESCU, M., ANGHELINA, F. V., Bratu, V., Romanian Reports in Physics, 68, 1, 2016, p. 278-293.

8.ENESCU, M., C., SIMULATION DE RESISTENCE A LA TRACTION ET COMPRESSION DANS UN COMPOSITE MACROMOLÉCULAIRE, U.P.B. Sci. Bull., Series B, Vol. 72, 3, 2010.

9.COSMELEATA, G., ENESCU, C., ZAHARIA, M., Materiaux composites a matrice organique, vol. I, Ed. Printech, Bucuresti, 2006.

10.RUSANESCU, C.O., RUSANESCU, M., JINESCU, C., BIRIS, S.S., Laser Hardening Influence of Metal Surfaces. Mat. Plast. 55, no. 2, 2018, p. 184.

11.DRUGA, C., NECULA, R., COTOROS, D., MICLAUS, R., REPANOVICI, A., NICA, S. A., Experimental Research Regarding the Thermomechanical Behaviour of PMMA During Recovery of Patients with J oint Replacements, Mat. Plast., 54, no. 4 , 2017, p. 645 12.HOESS A., LOPEZ A., ENGKVIST H., KARLSSON OTT M., PERSSON C., Materials Science and Engineering C, 62, Elsevier, 2016, p.274. 13.GOANTA, V., HADAR, A., LEITOIU, B., Mat. Plast., 47, no. 4, 2010, p.450.

14. DUARTE G. W., PELLEGRIN M. Z., JUNIOR J. F., SANTOS A.L.G., RIELLA H. G., FIORI M. A., J. Mat. Sci. Res., Vol 3 (1), 2014, p. 94.

15.HOLDANG G., Thermoplastic Elastomers in Applied Plastics Engineering Handbook: Processing and Materials, Elsevier, Oxford UK, 2011, p. 77.

16.GEORG GUTT, SONIA GUTT, DORU DUMITRU PALADE, FRIEDRICH KLEIN, KARLHEINZG. SCHMITT THOMAS, Testing and characterization of metallic materials, Technical Publishing House, Bucharest, 2000, p.180.

17.POPESCU, I. N., CATANGIU, A., STOIAN, E. V., UNGUREANU, D. N., Îndrumar de laborator, Materiale composite, Valahia University Press Târgoviste 2014.

18. MARIN, C., HADAR, A., POPA, F., ALBU, L., Modelarea cu elemente finite a structurilor mecanice - Editura ACADEMIEI si AGIR Bucuresti, 2002.

19. MARIN, C., HADAR, A., Metode numerice in ingineria mecanica, Editura Politehnica Pres Bucuresti, 2003.

20.SRIVATSAN TS, AL-HAJRI M, SMITH C., PETRAROLI M. The tensile response and fracture behavior of $2009 \mathrm{Al}$ alloy metal matrix composite. Mater Sci.Eng A, 346, 2003, p.91.

21.DOEL TJA, LORETTO MH, BOWEN P. Mechanical properties of Al based particulate metal-matrix composites.Composites 24,1993, p.270. 22.MCDANELS DL., Analysis of stress-strain, fracture and ductility behavior of Al matrix composites containing discontinuous silicon carbide reinforcement. Metall Trans A, 16A, 1985,p.1105.

23.TSAI TY., Polyethylene terephthalate-clay nanocomposites, editors Polymer-clay nanocomposites, New York: John Wiley \& Sons; 2000. p.173.

24.KATZ H.S., MILE SKI J.V., Editors Handbook of fillers for plastics. New York, Van Nostrand Reinhold Publ, 1997

\section{Manuscript received: 29.03 .2019}

